\title{
Complicaciones digestivas de la Fiebre Tifoidea
}

\author{
Drs. Teresa Alarcón D., Eric: Saeker W.
}

\begin{abstract}
The imcidence of digestive complications in $31 \mathbf{l}$ children aged two to thireen years with typhoid fever was found to be $13,18 \%$. The most frecuent complication was hepatitis $(6,11 \%)$ followed by digestive hemorhage (5.15\%).

Colecistitis and intestinal pertioration were estimated each one in less then l\%.

Lethality was $0,68 \%$. T wo patients died; ont of them because of colecistitis and the other one due to intestinal perforation, in addition both had other clinical disonders.

The features of digestive conplications of typhoid fever are briefly analized.
\end{abstract}

La Fiebre Tifoidea, entidad de alta prevalencia en la población infantil de nuestro país, habitualmente evoluciona como un cuadro séptico sin signos destacados de compromiso específico orgánico.

En algunas ocasiones, sin embargo, la Salmonella Typhi invade en forma preferencial algunos parénquimus alterando la fisonomía clásica de la enfermedad. Es lo que se conoce como

Servicio y Departamento de Pediatrá. Hospital San Juan de Dios. complicación de la enfermedad tífica, la que pasa a constituir en estos casos el hecho más relevante del cuadro clínico.

\section{MATERIAL Y METODO}

Interesados en conocer la magnitud de las complicaciones digestivas de la Fiebre Tifoidea, hemos revisado retrospectivamente 374 casos de niños entre 2 y 14 años hospitalizados por esta enfermedad en el Senvicio de Niños Mayores entre los años 1969 y 1979, de los cuales selecciona- 
RESULTADOS

IXCIDENCIA DE COMPLICACIONES DIGESTIVAS EN 311 CASOS DE FIEBRE TIFOIDEA

\begin{tabular}{lrc}
\hline Complicación & N. ${ }^{0}$ & $\%$ \\
\hline Hepatitis & 19 & 6,11 \\
Hem. Digest. & 16 & 5.15 \\
Colecistitis & 3 & 0.96 \\
Perforación Intest. & 3 & 0,96 \\
\hline Total & 41 & 13,18 \\
\hline
\end{tabular}

Comparativamente las complicaciones extra digestivas fueron mencrs frecuentes.

\section{INCIDENCIA DE COMPLICACIONES EXTRA DIGESTIVAS MAS FRECUENTES EN 31 I CASOS DE FIEBRE TIFOIDEA}

\begin{tabular}{lcc}
\hline Complicación E-D & N.0 & $\%$ \\
\hline $\begin{array}{l}\text { Complicación (Miocarditis) } \\
\text { Cardiovascular }\end{array}$ & 18 & 5.78 \\
$\begin{array}{l}\text { Complicación (Púrpura) } \\
\text { Hematológica }\end{array}$ & 4 & 1.28 \\
\hline \multicolumn{1}{c}{ Total } & 22 & 7,08 \\
\hline
\end{tabular}

mos 311 con hemocultivos y/o serologia a niveles significativos.

La mortalidad en el grupo de los 311 pacientes analizados fie $0.64 \%$; dos niños fallecieron a raiz de colecistitis y perforación intestinal respectivanente.

Analizaremos el comportamiento de cada complicación.

\section{HEPATITIS}

Fue la complicación más frecuente observada. 19 niños del total presentaron en el curso de su enfermedad coluria fugaz, ictericia y hepatomegalia. En dos de ellos que se encontraban hospitalizados al momento de aparecer la hepatitis, el aumento de volumen hepático fiue evidente y rápido, se hizo presente a los 12 y 20 días de evolución de la tifoidea.

En relación a los exámenes de laboratorio se observaron bilimbinemias que fluctuaron entre 0.3 y $9.2 \mathrm{mg} \%$; transaminasus piruvicas entre 45 y $350 \mathrm{U}$. por $100 \mathrm{ml}$; fosfatasas alcalinas entre $4,8 \mathrm{y}$
48 U.B. El tiempo de protrombina no se alteró salvo un caso cuyo valor descendió a $40 \%$.

En general los síntomas de hepatitis además de ser leves fueron de corta duración. La ictericia nunca se prolongó más allá de 11 días. Eiı dos casos se realizó biopsia percutánea, demostritndo el estudio histológico alteraciones inespecificas.

\section{HEMORRAGIA DIGESTIVA}

Presentaron sangramiento intestinal bajo un total de 16 niños $\{5,15 \%)$, cuyas edades fluctuaron entre 4 años 8 meses y 13 arios; diez eran de sexo femenino. En todos ellos la enfermedad tifica evoluciono la mayor parte del tiempo en el bogar ingresando el paciente al hospital en el momento de presentar la complicación. La hemorragia sutgió entre segunda a tercera semana de evolución caracterizándose por la presencia de dolor abdominal de tipo cólico, seguido de emisión por vía rectal de melend o bien sangre roja con coigulos, de mediana a cscasa cantidad y en dos a tres ocasiones durante un tiempo miximo de 3 días, De los 16 niños, 9 habian tenido diartea previamente y 7 habian recibido CAF durante dos a ocho dias.

La conducta terapétitica fue en todos los casos de tipo médico, se indicó transtusión excepcionalmente; el valor más bajo de hemoglobina observado fie $9.22 \%$. La evolución de todos los pacientes fue favorable con rápida mejoria de su estado general y cese de la hemorragia.

\section{COLECISTTTIS TIFICA}

Se observo en tres escolares de 7, 12 y 13 años de edad, respectivamente. La complicación se presentó entre la primera y segunda semana de evolución, a los 5, 8 y I3 días. Clínicamente se tradujo en dolor intenso en hipocondrio derecho con defensa muscular $y$ vesícula palpable; ninguno de los tres pacientes tuvo antecedentes de dispepsia. Uno de los pacientes había recibido CAF durante siete días.

Dos de los niños respondieron bien al tratamiento médico y superaron su tifoidea y complicación al cabo de 15 días de tratamiento, siendo dados de alta sanos. Uno de los escolares fine sometido a colecistografía luego del alta, la cual demostró exclusión vesicular, ignorándose su evolución ulterior.

El tercer caso, una niña, difiris en su evoluctón. La enfermedad fue grave desde su inicio, 
siendo intervenida quirúrgicamente por sospecha de perforación de viscera comprobándose la existencia de hidrops vesicular. El examen bacteriológicu de su contenido fue negativo. Se le trató con altas dosis de Quemicetina, corticoides $y$ Gentamicina; a pesar de ello fallece a los 20 dias de hospitalización. La necropsia demostró la existencia tanto en el intestino como en los pulmones de lesiones difisas que al patólogo impresionaron como debidas más bien a gérmenes anaerobios o estafilococos que a Salmonella.

El estudio de laboratorio demostró en dos oportunidades cierto grado de hipoglobulinemia (Alb:3.2 Glob.: 1.8 A:G,1.7). No se cuantificó las inmunoglobulinas.

\section{PERFORACION INTESTINAL}

Se observó en tres casos: Niña de 8 años, cuya evolución fue grave desde el comienzo y que ingresó con el diagnóstico de neumonía siendo tratada como tal; al día 14 de evolución intrahospitalaria ya con diagnóstico de F. Tifoidea y en tratamiento con Quemicetina, aparece dolor abdominal difuss, resistencia muscular de la pared abdominal difusa y signos de íleo paralítico, junto con aumento de la toxemia. Se intervino de urgencia encontrándose dos perforaciones en íleon reminal y peritonitis. El estudio anátomo-patológico confirmó la etiología tífica. Tuvo una evolución postoperatoria bastante tórpida por complicaciones que fueron superadas, siendo dada de alta en relativas buenas condiciones generales.

El segundo paciente fue un varón de 5 años y 5 meses de edad, tratado con CAF durante 14 días, el que a los 21 díts de enfermedad presenta signos de abdomen agudo. Es operado encontrándose perforaciones en ileon distal y peritonitis, lo que obligó a resecar el segmento intestinal afectado.

Nuestro tercer paciente, niña de 4 años de edad, poitadora de Nefropatóa crónica, recibió $\mathrm{CAF}$ durante seis dias. Estando ya afebril presentó signos de abdomen agudo con palpación de masa abdominal tipo plastrón, falleciendo antes de ingresar al pabellón quirúrgico.

\section{COMENTARIO}

La Fiebre Tifoidea por su carácter séptico puede en el curso de su evolución dar lugar a diferentes tipós de complicaciones según sean los órganos afectados.
En los 311 pacientes estudiados la mayor incidencia de complicación estuvo dada por aqueIlas relacionadas con el aparato-digestivo, $13.18 \%$, en tanto que las extra digestivas para el mismo grupo ascendieron a $7.06 \%$. La citra observada duplica aquellas obtenidas en adultos; $;^{7-8}$ este mayor valor se debió fundamentalmente a una mayor incidencia de hepatitis tifica. Sin embargo, la letalidad por complicación digestiva fue menor; ${ }^{8}$ en nuestro grupo sólo $0.64 \%$;

La mayor incidencia de complicaciones digestivas se explica por la localización primaria de la infección en intestino delgado, desde donde facilmente alcanza órganos contiguos como hígado y vesicula biliar; si el daño a la mucosa intestinal es severo, Heva a hemorragia y/o perforación del intestino.

Hemos querido distinguir complicación de lo que se considera manifestación propia inherente al cuadro clínico, como son la presencia de hepatoesplenomegalia, ( + en el $100 \%$ de los casos) y cambios en el tránsito intestinal, ya sea en el sentido de constipación o diarrea. Esta última la observamos en $53 \%$ de los casos, cifra más alta que $30 \%$ que señalan otras casuísticas.

La complicación más frecuente fue la hepatitis, con un cuadro clínico siempre leve. El estudio histológico mostró signos discretos de inflamación hepatocitaria y turnefacción turbia, alteraciones que señalan más bien una lesión de tipo tóxico que necrótica. Esto explica la escasa respuesta de la actividad de las transaminasas en el suero de estos pacientes. Los tifomas, lesiones granulomatosas descritas en casos de grave daño hepático, no se encontraron en el tejido biopsiado.

La hemorragia digestiva apanecio tardíamente en la evolución de la tifoidea. La encontramos en niños que recibieron tratamiento antibiótico oportuno, a la vez que hubo predilección por el sexo temenino, 10 a 16 casos. Su pronóstico parece ser mejor que en adultos, en los que la letalidad supera el $5 \% .^{4}$

Tànto la colecistitis como la perforación intestinal tuvieron una incidencia menor que $1 \%$ entre ambas complicaciones, significaron un $0,64 \%$ de letalidad para el grupo estudiado. Referente a la paciente fallecida por colecistitis, la causa del fracaso del tratamiento bien pudo deberse a déficit inmunitario, expresado en una baja tasa de globulinas, condición que no ałcanzó a ser estudiada, y en la presencia de lesiones aparen- 
temente producidas por anaerobios tanto en intestino como pulmones.

La niña fallecida por perforación intestinal era portadora de nefropatia crónica, con deterioro general que ocultó en parte la complicación y aceleró el deceso.

\section{RESUMEN Y CONCLUSIONES}

Estudiados 311 casos de Fiebre Tifoidea se observaron cumplicaciones digestivas en $13.18 \%$ de ellos, siendo la más frecuente, la Hepatitis (6.11\%), segujda de la Hemorragia digestiva $(5.15 \%)$.

Tanto la Colecistitis como la Perforación se observaron en menos del $1 \%$ de los casos, adquiriendo importancia por constituir causa de letalidad.

La yran mayoria de los pacientes evolucionaron favorablemente con tratamiento médico sin requerir cirugía.

\section{REFERENCIAS}

'Fanta, E., Lobos, H., y Hurtodo, R, Algunos conceptos moxler- nos sobre etiopatogenia e inmunulogia de Fiebre Tiloidea. Pediatria. 15: 259-261, 1972.

${ }^{2}$ Parrochio. E.: Rojas, R., y Pinto, M. E. Tratamiento de la Fiebre Tifoidea. Boletín del Hospital San Juan de Dios. 22: $71-7 \overrightarrow{7}, 1975$.

${ }^{3}$ Olaxarria, F.; Fadic, R., y Tezanas P., S. Ictericia en Fiebre Tifoidea durante la epidemia del año 1968. Rev. Med. Valparaistr. 22: $211-215,1969$.

1 Pincheira V., W. y Lazo $I_{\text {, }}$ M. Compliaciones quiringicas de 1 a Fiepre Tiloide ar. Arch. Sor. (Vír. Chile. 23i2): 362-387, 1971.

${ }^{5}$ Goic, A y Hurtado, R. Colecistitis aguda en la Fiebre Tifoidea. Rev. Méd. Chile 94: 611)615, 1966.

${ }^{6}$ Donoso, $P_{;}$Kraljecic, H.; Bocal, H.; Mendoza, A.; Lavat, E., Murios, N. El crompomiso cardíaco en el curso de la Fiebre Tifoidea. Rev. Méd. Chile 93: 131-157, 1955.

${ }^{7}$ Borgonit, J, M. y Peurson, E. Fiebre Tifoidea y Paratifoidea. Análisis clínico y de laboratorio de un brote estacional. Rev. Méd. Chile 9.3: 145-151, 1965.

" Satcedu, M.: Lacal, E.; Hashán, M.; Bargoño, J. M., $y$ Weitmant, J. Complicaciones y letalidad de la Fiebre Tifoidea $y$ de los Paratifus A y B. Rev, Méd. Chile 95: 744, 1967.

${ }^{9}$ Borkoño D. J. M. Nuevos aportes a la Epiderniología de la Fielore Tifoidea en la Provincia de Santiago con especial referencia al brote epidémico estucional 1956-1957. Fev. Med. Chile 86: 413, 1958 .

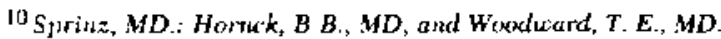
Histopyatologia of the lipper Small Intestine in Typhoid Fever. Biopsy Study of Experimental Visease in man. Am. J. Dig. Dis. 11 (8): 615-624, 1969 . 